\title{
Influence of Emotional Competence on Well-being
}

\section{among Adolescents}

\author{
Rashida Masrat ${ }^{1}$, Mohd Amin Wani ${ }^{2}$, Dr. Shah Alam ${ }^{3}$
}

\section{ABSTRACT:}

An attempt has been made to study the influence of Emotional Competence on Well-being among Male and Female Adolescents. The present study was conducted on 100 Adolescents (Male $n=50$ \& Female n=50) using Simple Random Sampling. Emotional Competence and Wellbeing was assessed by using Emotional Competence Scale developed by J. S. Fulton Paiva and Dr. M. Suresh Kumar (2009) and Well-being scale developed by Jagsharanbir Singh and Dr. Asha Gupta (2001). The scale of Well-being consists of five dimensions viz ; Physical, Mental, Social, Emotional and Spiritual Well-being. After analyzing the data by Simple Linear Regression, the first finding showed the Emotional Competence appeared as a significant predictor of overall Well-being among Male Adolescents. It implies that there is a significant positive correlation between Emotional Competence and Overall Well-being among Male Adolescents. The second finding indicates that Emotional competence appeared as significant factor of Mental, Social, Emotional and Spiritual Well-being but not as factor of Physical Wellbeing. The third finding showed that Emotional Competence also appeared as a significant predictor overall Well-being among Female Adolescents. . It implies that there is a significant positive correlation between Emotional Competence and Overall Well-being among Female Adolescents. The last finding reveals that Emotional Competence significantly influences the degree of Physical and Emotional Well-being but doesn't influence the degree of Mental, Social and Spiritual Well-being. Well-being is a leading issue for every Individual, if Emotional Competence leads towards better Well-being among Individuals, let them express their inner feelings without any suppression.

Keywords: Emotional Competence, Well-being, Adolescents

Adolescence is a period of transition in which a person faces challenges and difficulties that may lead him into confusion and troubles. Therefore, the Emotional Competence is critical to adolescent's development.

\footnotetext{
${ }^{1}$ Research Scholar, Deptt of Psychology, AMU Aligarh.

${ }^{2}$ Research Scholar, Deptt of Psychologhy, AMU Aligarh

${ }^{3}$ Associate Professor, Deptt. of Psychology, AMU Aligarh.
} 
It is that stage where the individual can either build up or destroy his/her career. It has been rightly said that adolescence is a period of stress and strain, storm and strike. In this competitive world, competition in every field particularly in education is very high for adolescents. Therefore, the adolescents need to have more competence to deal with the situations effectively. Adolescents should be able to cope with the stress, manage their emotions, and improve selfesteem, confidence, and decision making which leads to increase their wellbeing. Adolescents are the beneficial resources of the society. If an adolescent is competent, he/she will be able to get the job at the right place, which is beneficial for his own development and the development of the nation as a whole. However, the notion of emotional competence has acquired more attention and has been denoted as a strong predictor of success in life. Emotional competence (EC) can be understood as a group of general skills that can be applied to many types of emotion-related skills. The ability to identify and discriminate emotions is especially important in youth development and may be influenced by a person's initial orientation to his/her emotionrelated problems. When an individual is less emotionally competent, he/she tries to keep away from thoughts and feelings related to the problems coming in his/her way. In such a case, he/she may fail to recognize emotions and thus be less able to resolve emotional problems in useful ways and less likely to accept his/her own feelings. Incompetent individual's wellbeing is not guaranteed whereas competent adolescents pass all the hurdles of life. Emotional competence developing through the lifespan include emotional expression and experience, understanding emotions of self and others, and emotion regulation. Children become increasingly emotionally competent over time, and growing evidence suggests that such emotional competence contributes to their concurrent social competence and well-being, as well as to later social and academic outcomes (Denham et al., 2003; Denham, Brown, \& Domitrovich, 2010; Denham \& Burton, 2003). Therefore, it seemed important to conduct a study in which Adolescents could be assessed in terms of their Emotional Competence and Well-being.

\section{Emotional competence}

Emotional competence refers to a person's ability in expressing or releasing their inner feelings (emotions). It implies an ease around others and determines our ability to effectively and successfully lead and express. Doing a thing is quite different from doing it well, where one can produce the type of effects, one desire, (White, 1959) may be termed as competence. To achieve and maintain a feeling of adequacy, the individual has to acquire a few workable assumptions about the world, Where need for competence emerges as most of the fundamental motive of life, because we survive through competence, grow through competence and actualize ourselves through competence (Allport, 1961). Boyatzis et al. offers a descriptive definition of emotional competence, 'a person demonstrates the self-awareness, self-management, social awareness and social skills at appropriate times and ways in sufficient frequency to be effective in the situation'. Emotional competence contributes to the achievement of both intrapersonal (e.g., individual well-being) and interpersonal (e.g., maintenance of important social relationships) well-being (Eisenberg et al., 2001; Shipman and Zeman, 2001). Indeed, difficulties in identifying feelings and emotions underlie depression, anxiety, delinquency, and impaired friendships (Honkalampi et al., 2009). ), emotional competence as an understanding of one's own and others' emotions and the ability to display emotions in a situation ally appropriate manner (Eisenberg et al., 1999). Individuals who lack these skills are often characterized in terms of alexithymia, which is a marked inability to identify, describe, and express one's emotions. 


\section{Influence of Emotional Competence on Well-being among Adolescents}

\section{Wellbeing}

"Well-being is more than just happiness as well as feeling satisfied and happy,well-being means developing as a person, being fulfilled, and making a contribution to the community" (Shah \& Mark, 2004).

Well- being is one of the most important goals, which individuals as well as societies strive for. The term denotes that something is in a good state. It does not specify what the "something" is and what is meant by 'good'. Wellbeing can be specified in two ways: first by specifying the 'what' and secondly by spelling out the criteria of wellness (Veenhoven, 2004). So many terms such as happiness, satisfaction, hope, positive effect, well-being and quality of life have been used in the literature synonymously and interchangeably. The word 'well-being' is mostly used for specific variety of goodness, for example, living in a good environment, being of worth for the world, being able to cope with life, enjoying, etc. The concept of "wellbeing" suffers from definitional problem. In their systematic review of the definition, Pollard and Lee (2003) describe well-being as "a complex, multi-faceted construct that has continued to elude researchers' attempts to define and measure it". Wellbeing has been defined as a dynamic state characterized by reasonable amount of harmony between individual's abilities, needs, expectations, environmental demand, and opportunities (Levi, 1987). It is connotative as a harmonious satisfaction of one's desires and goals (Checola, 1975). Well-being involves subjective satisfaction and individual pleasure depending upon psychological status of the individual and his environmental conditions. Competent emotional functioning is essential for well-being. The ability to recognize, identify, and describe one's own and others' feelings are considered key aspects to emotional competence. While emotional competence includes aspects of emotion regulation (Shipman and Zeman, 2001).

\section{LITERATURE REVIEW}

Poor emotional competence have negative implications for youths' well-being, including difficulty forming friendships and poorer academic adjustment (Eisenberg et al., 1999).

Wellbeing has been found to decrease in early to middle adolescence and reach its lowest point at age; emotional competence is generally hypothesized to be a good predictor of one's sense of subjective well-being. There is an assumption that emotionally competent individuals will have richer sense of subjective well-being. Zeidner and Olnick-Shemesh,(2010) summarized four reasons for this assumption. First, emotionally competent individuals are more aware of their emotions and more able to regulate them, which will contribute to experience higher levels of well-being. Second, the individuals with emotional competence are assumed to have richer social connections and are able to demonstrate better coping strategies. Third, with more accurate interpretation of the information yielded by the emotions and the environment, individuals with emotional competence can sustain a better sense of wellbeing. Fourth, provided that those with emotional competence would have the propensity to experience more positive affects, individuals are more prone to a richer sense of subjective well-being.

Ciarrochi and Scott,(2006) carried out a longitudinal study to investigate causal relations and the link between emotional competence and well-being. They found that people with effective 
problem orientation were less likely to experience depression, anxiety, and stress and were more likely to experience positive moods. Catalano et al. state that the enhancement of competence can help prevent other negative outcomes and is indicative of positive youth development.

Individuals with high EC are able to identify their emotions as well as those of others, express them in a socially acceptable manner, understand their causes and consequences, regulate them when they are not appropriate to the context or to their goals, and use them to enhance thoughts and actions (Mayer \& Salovey, 1997). While those individuals are able to take advantage of emotions without letting the latter lead them astray, individuals with low EC have a hard time taking into account the information emotions convey and are commonly overwhelmed by them (Mikolajczak, Quoidbach, Kotsou, \& Nelis, 2009 )

Nelis, et al.(2011) and Kotsou, et al.(2011) showed that improving the level of EC through a brief psychological intervention led to increased well-being, decreased cortisol and somatic complaints, enhanced social relationships and greater employability.

\section{OBJECTIVES}

1. To see the influence of Emotional Competence on Overall Well-being among Male adolescents.

2. To examine the influence of Emotional Competence on different dimensions of Wellbeing (Physical, Mental, Social, Emotional and Spiritual) among Male adolescents.

3. To see the influence the influence of Emotional Competence on Overall Well-being among Female adolescents.

4. To examine the influence of Emotional Competence on different dimensions of Wellbeing (Physical, Mental, Social, Emotional and Spiritual) among Female adolescents.

\section{RESEARCH QUESTIONS}

Taking into consideration the objectives of the study, the following Research questions were formulated.

1. Is there any influence of Emotional Competence on Overall Well-being among Male adolescents?

2. Is there any influence of Emotional Competence on different dimensions of Wellbeing (Physical, Mental, Social, Emotional and Spiritual) among Male adolescents?

3. Is there any influence the influence of Emotional Competence on Overall Well-being among Female adolescents?

4. Is there any influence of Emotional Competence on different dimensions of Wellbeing (Physical, Mental, Social, Emotional and Spiritual) among Female adolescents? 


\section{METHODOLOGY}

\section{Tools Used}

Emotional Competence Scale

Emotional competence scale developed by J. S. Fulton Paiva and Dr. M. Suresh Kumar (2009) w as used to assess the Emotional Competence scores of participants. It can be administered to all $\mathrm{t}$ he age groups. It contains 35 items ranging from always to never. 35 minutes is the average time to complete. . The items in the scale provide the adequate content valid. Reliability co-efficient of correlation between forms is 0.712, equal-length Spearman-Brown is 0.721, Guttman Split-hal $\mathrm{f}$ is 0.719 and unequal-length Spearman-Brown is 0.719 .

Well-being Scale

Wellbeing scale by Jagsharanbir Singh and Dr.Asha Gupta, (2001) consists of 50 items ranging from very much to not so much. It contains five dimensions such as physical wellbeing, mental wellbeing, emotional wellbeing, spiritual wellbeing. Each dimension contains 10 items. This scale has an excellent Test-retest reliability (0.98) and Spilit half reliability(0.96).Content and Concurrent validity was established. Concurrent validity of the scale was determined by comparing it the scores of Subjective Well-being Inventory by Sall and Nagpal (1992). Correlation between Subjective Well-being inventory and different dimensions of this scale were $-0.45,0.78,-0.90,0.28$ and 0.18 respectively. The total correlation was found to be 0.53

\section{Sample}

The students of Aligarh Muslim University served as sample in this study. Simple random sampling was used to select the participants. The total no. of participants consisted of 100 adolescents, with equal number of Male $(n=50)$ and Female $(n=50)$.

\section{Procedure}

The data of the present study was collected through personal contact with the participants individually or in small groups. Before administering the tools, the purpose of the study was explained to the participants and they were assured that their responses would be kept confidential and will be used for research purpose. After establishing the rapport with the participants, they were requested to fill the emotional competence scale and the scale of wellbeing. Emotional competence scale took 35 mints where as wellbeing scale took 40 mints to complete. In this way, the data was collected from the participants. The obtained data was analyzed by the means of simple linear regression. 


\section{RESULTS}

Table 1: Represents Linear Regression Analysis to find out relationship between Emotional Competence and Well-being of Male Adolescents.

\begin{tabular}{|l|r|r|r|r|}
\hline \multicolumn{5}{|c|}{ Model Summary } \\
\hline Model & \multicolumn{1}{|c|}{$\mathrm{R}$} & R Square & $\begin{array}{c}\text { Adjusted R } \\
\text { Square }\end{array}$ & $\begin{array}{r}\text { Change Statistics } \\
\text { R Square Change }\end{array}$ \\
\hline 1 & .899 & .808 & .804 & .808 \\
\hline \multicolumn{5}{|l|}{ a. Predictors: (Constant), Emotional Competence Male } \\
\hline
\end{tabular}

The above table shows Simple Linear Regression analysis of Emotional Competence, it showed that Emotional Competence appeared as significant predictor of Well-being. It was found that Emotional Competence (Predictor) was upheld as significant predictor of Well-being (Criterion). This table shows the model summary, which indicates one predictor of the model. The correlation was found to be $\mathrm{R}=.899$. $\mathrm{R}$ Square change mentioned in the above table indicates the actual contribution of predictor variable to the criterion variable. Therefore, the original covariance, the magnitude of independent variable, which contributed to the dependent variable (Well-being), came out as $80.8 \%$.

Table 2: Represents the details of Coefficients between Emotional Competence and Well-being of Male Adolescents.

\begin{tabular}{|c|c|c|c|c|c|c|}
\hline \multicolumn{7}{|c|}{ Coefficients } \\
\hline \multirow{2}{*}{\multicolumn{2}{|c|}{ Model }} & \multicolumn{2}{|c|}{$\begin{array}{c}\text { Unstandardized } \\
\text { Coefficients } \\
\end{array}$} & \multirow{2}{*}{$\begin{array}{c}\text { Standardized } \\
\text { Coefficients }\end{array}$} & \multirow[b]{2}{*}{$\mathrm{t}$} & \multirow[b]{2}{*}{ Sig. } \\
\hline & & $\mathrm{B}$ & Std. Error & & & \\
\hline \multirow[t]{2}{*}{1} & (Constant) & 181.190 & 2.991 & & 60.579 & .000 \\
\hline & $\begin{array}{l}\text { Emotional Competence } \\
\text { Male }\end{array}$ & .342 & .024 & .899 & 14.233 & .000 \\
\hline & dent Variable: Well-be & le ove & & & & \\
\hline
\end{tabular}

The above table clearly shows that Emotional Competence (the predictor variable) influenced Well-being (Criterion). The Statistical value given in the table was found to be $t=14.233$ which is significant for above-mentioned predictor that is Emotional Competence indicating a relationship between predictor and criterion variable Well-being.

The value of Partial Correlation is $r=.899$, therefore predictor significantly influenced the degree of Well-being. This finding indicates that Emotional Competence appeared as factor of Well-being among Male adolescents. The table indicates a significant positive correlation 
between Emotional Competence and Well-being among Male adolescents. It means that when Emotional Competence increases, Well-being also increases and when Emotional Competence decreases Well-being decreases.

Table 3: Represents Linear Regression Analysis to find out relationship between Emotional Competence and Different dimensions of Well-being (Physical, Mental, Social, Emotional and Spiritual) of Male Adolescents.

\begin{tabular}{|c|c|c|c|c|}
\hline \multicolumn{5}{|c|}{ Model Summary } \\
\hline Model & $\mathbf{R}$ & R Square & $\begin{array}{l}\text { Adjusted R } \\
\text { Square }\end{array}$ & $\begin{array}{c}\text { Change Statistics R } \\
\text { Square Change }\end{array}$ \\
\hline $\begin{array}{l}\text { Physical Well-being } \\
\text { Male }\end{array}$ & .035 & .001 & -.020 & .001 \\
\hline Mental Well-being Male & .927 & .859 & .856 & .859 \\
\hline Social Well-being Male & .689 & .474 & .463 & .474 \\
\hline $\begin{array}{l}\text { Emotional Well-being } \\
\text { Male }\end{array}$ & .725 & .526 & .516 & .526 \\
\hline $\begin{array}{l}\text { Spiritual Well-being } \\
\text { Male }\end{array}$ & .344 & .118 & .100 & .118 \\
\hline a. Predictors: (Constant), & tional & 1 Competen & Iale & \\
\hline
\end{tabular}

The above table shows Simple Linear Regression analysis of Emotional Competence, it showed that Emotional Competence appeared as insignificant predictor of Physical Well-being but significant predictor of Mental, Social, Emotional and Spiritual Well-being among Male adolescents. This table shows the model summary, which indicates one predictor of the model. The correlation on different dimensions of Well-being was found to be $\mathrm{R}=.035, .927, .689, .725$ and .344 respectively. $\mathrm{R}$ Square change mentioned in the above table indicates the actual contribution of predictor variable to the criterion variable. Therefore, the original covariance, the magnitude of independent variable, which contributed to the dependent variable (Different Dimensions of Well-being), came out as $00.1 \%, 85.9 \%, 47.4 \%, 52.6 \%$ and $11.8 \%$ respectively. 
Table 4: Represents the details of Coefficients between Emotional Competence and Different Dimensions of Well-being (Physical, Mental, Social, Emotional and Spiritual) of Male Adolescents.

\begin{tabular}{|c|c|c|c|c|c|}
\hline \multicolumn{6}{|c|}{ Coefficients } \\
\hline \multirow[b]{2}{*}{ Model } & \multicolumn{2}{|c|}{$\begin{array}{c}\text { Unstandardized } \\
\text { Coefficients }\end{array}$} & \multirow{2}{*}{\begin{tabular}{|c|} 
Standardized \\
Coefficients
\end{tabular}} & \multirow[b]{2}{*}{$\mathbf{t}$} & \multirow[b]{2}{*}{ Sig. } \\
\hline & B & Std. Error & & & \\
\hline Constant & 42.603 & 6.909 & & 6.167 & .000 \\
\hline Emotional Competence Male & .013 & .055 & .035 & .243 & .809 \\
\hline Constant & 5.257 & 2.313 & & 2.273 & .028 \\
\hline Emotional Competence Male & .317 & .019 & .927 & 17.079 & .000 \\
\hline Constant & 34.905 & 1.495 & & 23.340 & .000 \\
\hline Emotional Competence Male & .079 & .012 & .689 & 6.580 & .000 \\
\hline Constant & 61.358 & 2.243 & & 27.352 & .000 \\
\hline Emotional Competence Male & -.131 & .018 & -.725 & -7.295 & .000 \\
\hline Constant & 37.067 & 3.121 & & 11.877 & .000 \\
\hline Emotional Competence Male & .064 & .025 & .344 & 2.537 & .014 \\
\hline
\end{tabular}

Dependent Variable: Male (Physical Well-being, Mental Well-being, Social Well-being, Emotional Well-being and Spiritual Well-being)

The above table clearly shows that Emotional Competence (the predictor variable) influenced Mental, Social, Emotional and Spiritual Well-being (Criterion) but does not influence Physical Well-being (Criterion). The Statistical values given in the table were found to be $t=17.079$, $6.580,-7.295,2.537$ and .243 respectively.

These t-values are significant for above-mentioned predictor that is Emotional Competence indicating a relationship between predictor and criterion variables (Mental, Social, Emotional and Spiritual) Well-being and indicating an insignificant relationship between predictor and criterion variable (Physical Well-being). 
The values of Partial Correlation is $\mathrm{r}=.035, .927, .689,-.725$ and .344 . Therefore, predictor significantly influenced the degree of Mental, Social, Emotional and Spiritual Well-being, but does not influence the degree of Physical Well-being. These findings indicate that Emotional Competence appeared as factor of different dimensions of Well-being except Physical Wellbeing among Male adolescents. The table indicates a significant positive correlation exists between Emotional Competence and Mental, Social, and Spiritual Well-being, a significant negative correlation between Emotional Competence and Emotional Well-being and indicates an insignificant positive Correlation between Emotional Competence and Physical Well-being.

Table 5: Represents Linear Regression Analysis to find out relationship between Emotional Competence and Well-being of Female Adolescents.

\begin{tabular}{|l|r|r|r|r|}
\hline \multicolumn{5}{|c|}{ Model Summary } \\
\hline Model & \multicolumn{1}{|c|}{$\mathrm{R}$} & R Square & $\begin{array}{c}\text { Adjusted R } \\
\text { Square }\end{array}$ & $\begin{array}{l}\text { Change Statistics } \\
\text { R Square Change }\end{array}$ \\
\hline 1 & .397 & .158 & .140 & .158 \\
\hline \multicolumn{5}{|l|}{ a. Predictors: (Constant), Emotional Competence Female } \\
\hline \multicolumn{5}{|l}{} \\
\hline
\end{tabular}

The above table shows Simple Linear Regression analysis of Emotional Competence, it showed that Emotional Competence appeared as significant predictor of Well-being. It was found that Emotional Competence (Predictor) was upheld as significant predictor of Well-being (Criterion). This table shows the model summary, which indicates one predictor of the model. The correlation was found to be $\mathrm{R}=.397$. $\mathrm{R}$ Square change mentioned in the above table indicates the actual contribution of predictor variable to the criterion variable. Therefore, the original covariance, the magnitude of independent variable, which contributed to the dependent variable (Well-being), came out as $15.8 \%$. 
Table 6: Represents the details of Coefficients between Emotional Competence and Well-being of Female Adolescents.

\begin{tabular}{|c|c|c|c|c|c|c|}
\hline \multicolumn{7}{|c|}{ Coefficients } \\
\hline & \multirow[b]{2}{*}{ Model } & \multicolumn{2}{|c|}{$\begin{array}{c}\text { Unstandardized } \\
\text { Coefficients }\end{array}$} & \multirow{2}{*}{$\begin{array}{c}\text { Standardized } \\
\text { Coefficients } \\
\text { Beta }\end{array}$} & \multirow[b]{2}{*}{$\mathrm{T}$} & \multirow[b]{2}{*}{ Sig. } \\
\hline & & $\mathrm{B}$ & Std. Error & & & \\
\hline \multirow[t]{2}{*}{1} & (Constant) & 175.248 & 11.942 & & 14.675 & .000 \\
\hline & \begin{tabular}{|l} 
Emotional Competence \\
Female
\end{tabular} & .324 & .108 & .397 & 2.996 & .004 \\
\hline
\end{tabular}

The above table clearly shows that Emotional Competence (the predictor variable) influenced Well-being (Criterion). The Statistical value given in the table was found to be $\mathrm{t}=2.99$ which is significant for above-mentioned predictor that is Emotional Competence indicating a relationship between predictor and criterion variable Well-being.

The value of Partial Correlation is $r=.397$, therefore predictor significantly influenced the degree of Well-being; this finding indicates that Emotional Competence appeared as factor of Well-being among Female adolescents. The table indicates a significant positive correlation exists between Emotional Competence and Well-being among Female adolescents. It means that when Emotional Competence increases, Well-being also increases and when Emotional Competence decreases Well-being also decreases.

Table 7: Represents Linear Regression Analysis to find out relationship between Emotional Competence and Different dimensions of Well-being (Physical, Mental, Social, Emotional and Spiritual) of Female Adolescents.

\begin{tabular}{|l|r|r|r|r|}
\hline \multicolumn{1}{|c|}{ Model } & \multicolumn{1}{|c|}{ Rodel Summary } \\
\hline Physical Well-being Female & .529 & .280 & \multicolumn{1}{c|}{$\begin{array}{l}\text { Adjusted } \\
\text { R Square }\end{array}$} & $\begin{array}{c}\text { Change Statistics R } \\
\text { Square Change }\end{array}$ \\
\hline Mental Well-being Female & .075 & .006 & -.015 & .280 \\
\hline Social Well-being Female & .080 & .006 & -.014 & .006 \\
\hline $\begin{array}{l}\text { Emotional Well-being } \\
\text { Female }\end{array}$ & .333 & .111 & .092 & .006 \\
\hline $\begin{array}{l}\text { Spiritual Well-being } \\
\text { Female }\end{array}$ & .114 & .013 & -.008 & .013 \\
\hline \begin{tabular}{l} 
a. Predictors: (Constant), Emotional Competence Female \\
\hline
\end{tabular}
\end{tabular}


The above table shows Simple Linear Regression analysis of Emotional Competence, it showed that Emotional Competence Appeared as significant predictor of Physical and Emotional Wellbeing but insignificant predictor of Mental, Social, and Spiritual Well-being among Female adolescents. This table shows the model summary, which indicates one predictor of the model. The correlation on different dimensions of Well-being was found to be $\mathrm{R}=.529, .075, .080, .333$ and .114 respectively. $\mathrm{R}$ Square change mentioned in the above table indicates the actual contribution of predictor variable to the criterion variable. Therefore the original covariance, the magnitude of independent variable which contributed to the dependent variable (Different Dimensions of Well-being) came out as $28.0 \%, 00.6 \%, 00.6 \%, 11.1 \%$ and $01.3 \%$ respectively.

Table 8: Represents the details of Coefficients between Emotional Competence and Different Dimensions of Well-being (Physical, Mental, Social, Emotional and Spiritual) of Female Adolescents.

\begin{tabular}{|c|c|c|c|c|c|}
\hline \multicolumn{6}{|c|}{ Coefficients } \\
\hline \multirow[b]{2}{*}{ Model } & \multicolumn{2}{|c|}{$\begin{array}{c}\text { Unstandardized } \\
\text { Coefficients }\end{array}$} & \multirow{2}{*}{\begin{tabular}{|c|}
$\begin{array}{c}\text { Standardized } \\
\text { Coefficients }\end{array}$ \\
Beta \\
\end{tabular}} & \multirow[b]{2}{*}{$\mathbf{t}$} & \multirow[b]{2}{*}{ Sig. } \\
\hline & B & Std. Error & & & \\
\hline Constant & 18.456 & 5.409 & & 3.412 & .001 \\
\hline Emotional Competence Female & .212 & .049 & .529 & 4.320 & .000 \\
\hline Constant & 45.027 & 8.935 & & 5.039 & .000 \\
\hline Emotional Competence Female & -.042 & .081 & -.075 & -.518 & .607 \\
\hline Constant & 39.615 & 6.792 & & 5.832 & .000 \\
\hline Emotional Competence Female & .034 & .062 & .080 & .558 & .580 \\
\hline Constant & 22.252 & 7.925 & & 2.808 & .007 \\
\hline Emotional Competence Female & .176 & .072 & .333 & 2.444 & .018 \\
\hline Constant & 49.899 & 7.694 & & 6.485 & .000 \\
\hline Emotional Competence Female & -.055 & .070 & -.114 & -.793 & .431 \\
\hline $\begin{array}{l}\text { Dependent Variable: Fema } \\
\text { Emotional Well-being and } \mathrm{Sp}\end{array}$ & $\begin{array}{ll}l 1 \\
1-b e\end{array}$ & 1-being, $\mathrm{N}$ & 11 & & \\
\hline
\end{tabular}

The above table clearly shows that Emotional Competence (the predictor variable) influenced Physical and Emotional Well-being (Criterion) but does not influence Mental, Social and 
Spiritual Well-being (Criterion). The Statistical values given in the table were found to be $\mathrm{t}=$ $4.320,2.444,-.518, .558$ and -.793 respectively.

These t-values are significant for above mentioned predictor that is Emotional Competence indicating a relationship between predictor and criterion variable (Physical and Emotional) Wellbeing and also indicating an insignificant relationship between predictor and criterion variable (Mental, Social and Spiritual Well-being).

The values of Partial Correlation is $r=.529,-.075, .080, .333$ and -.114 . Therefore, predictor significantly influenced the degree of Physical and Emotional Well-being, but does not influence the degree of Mental, Social and Spiritual Well-being. These findings indicate that Emotional Competence appeared as factor of Physical and Emotional Well-being. The table indicates a significant positive correlation exists between Emotional Competence and Physical and Emotional Well-being, an insignificant positive correlation between Emotional Competence and Social Well-being and also indicates an insignificant negative Correlation between Emotional Competence and Mental and Spiritual Well-being.

\section{DISCUSSION}

The present study was aimed to see the influence of Emotional competence on Well-being among male and female adolescents. The findings revealed that Emotional Competence appeared as a significant predictor of Well-being among both male and female adolescents. These findings are consistent with the findings of Zeidner and Olnick-Shemesh (2010), who found that emotionally competent individuals are more aware of their emotions and more able to regulate them, which will contribute to experience higher levels of well-being. Second, the individuals with emotional competence are assumed to have richer social connections and are able to demonstrate better coping strategies. Third, with more accurate interpretation of the information yielded by the emotions and the environment, individuals with emotional competence can sustain a better sense of well-being.

After determining the influence of Emotional competence on different dimensions of well-being among male and female adolescents. The findings revealed that Emotional Competence appeared as significant predictor of Mental, Social and Spiritual well-being among male adolescents, a significant positive correlation was also found between Emotional competence and Physical well-being and Emotional well-being among female adolescents. The overall well-being is consisted of Five dimensions that is Physical, Mental, Social, Emotional and Spiritual Wellbeing. These findings could be supported by the study conducted by Nelis et al. (2011) and Kotsou et al. (2011) they showed that improving the level of EC through a brief psychological intervention led to increased well-being, decreased cortisol and somatic complaints, enhanced social relationships and greater employability. Catalano et al, (2004) state that the enhancement of competence can help prevent other negative outcomes and is indicative of positive youth development. 
Insiginificant correlations were found between Emotional competence and Physical Well-being among male adolescents. It means that if EC increases it neither influences nor deteriorates the physical well-being of male adolescents. The reason could be that the males are more curious about their physical built. Therefore they engage themselves in different types of physical exercises. As a result, their well-being remains intact. It hardly matters if male adolescents are emotionally competent or incompetent, they take care of their physical health in a best possible manner.

Insignificant correlations were also found between emotional Competence and Mental, Social and Spiritual Well-being among female adolescents. In the present scenario, females face stressful and anxiety provoking situations but with a mindset of competition with others they try to cope with these situations. Females also engage themselves in social gatherings and have friends more than the males. Females are more diverted towards their religion, they cannot discriminate in the name of religion. So far as the sample was taken from A.M.U. The religious environment might also be a factor for predicting their spiritual well-being. In the light of the above points, we can say that the Mental, Social and Spiritual well-being of Females remained intact whether they were emotionally competent or emotionally incompetent.

\section{CONCLUSION}

Emotional competence can have positive implications for adolescents' Well-being including better adjustment, good academic achievement, forming friendship, participate social gatherings etc. Emotionally competent adolescents can be able to cope with the stress and can sustain better sense of wellbeing, develop the confidence for attaining their goals.

\section{REFERENCES}

1. Bukowski, A. E., Schwartzman, D. M., Stack, and White, D. R. (1998). Eds., Plenum Press,

2. Catalano, R. F., Berglund, M. L., Ryan, J. A. M., Lonczak, H. S., and Hawkins, J. D. (2004). "Positive youth development in the UnitedStates: research findings on evaluations of positive youth development programs," Annals of the American Academy of Political and Social Science, vol. 591, pp. 98-124.

3. Chekola, N. G. (1975). The concept of happiness. Doctoral dissertation. Michigan University, Dissertation Abstracts International.

4. Ciarrochi, and Scott, G. (2006). "The link between emotional competence and well-being: a longitudinal study," British Journal of Guidance and Counselling, vol. 34, no. 2, pp. 231-243.

5. Ciarrochi, J., and Scott, G. (2006). "The link between emotional competence and wellbeing: a longitudinal study," British Journal of Guidance and Counselling, vol. 34, no. 2, pp. 231-243. 
6. Compas, B. E., and Harding, A. "Competence across the lifespan: lessons from coping with cancer," in Improving

7. Csikszentmihalyi, M., and Hunter, J. (2003). "Happiness in everyday life: the uses of experience sampling," Journal of Happiness Studies, vol. 4, pp. 185-199.

8. Denham, S. A., \& Burton, R. (2003). Social and emotional prevention and intervention programming for preschoolers. New York: Kluwer-Plenum.

9. Denham, S. A., Blair, K. A., DeMulder, E., Levitas, J., Sawyer, K. S., Auerbach-Major, S. T., et al. (2003). Preschoolers' emotional competence: Pathway to mental health? Child Development, 74, 238-256.

10. Denham, S. A., Brown, C. E., \& Domitrovich, C. E. (2010). Plays nice with others: Social-emotional learning and academic success. Early Education and Development, 21, 652-680. doi: 10.1080/10409289.2010.497450

11. Eisenberg, N. (1998). "The socialization of socio emotional competence," in Improving Competence Across the Lifespan: Stack, and D. R. White, Eds., Plenum Press, New York, NY, USA.

12. Eisenberg, N., Cumberland, A., Spinrad, T. L., Fabes, R. A., Shepard, S. A., Reiser, M., et al. (2001). The relations of regulation and emotionality to children' externalizing and internalizing problem behavior. Child Dev. 74, 1112-1134.doi: 10.1111/14678624.00337

13. Eisenberg, N., Fabes, R. A., Shepard, S. A., Guthrie, I. K., Murphy B. C., and Reiser, M. (1999). Parental reactions to children's negative emotions longitudinal relations to quality of children are social functioning. Child Dev. 70,513-534.doi: 10.1111/14678624.00037.

14. Frauenknecht, M., and Black, D. R. (1995). "Social Problem-Solving Inventory for Adolescents (SPSI-A): development and preliminary psychometric evaluation," Journal of Personality Assessment, vol. 64, no. 3, pp. 522-539.

15. Garner, P. W. (2010). "Emotional competence and its influences on teaching and learning," Educational Psychology Review, vol. 22, no. 3, pp. 297-321.

16. Kotsou I, Nelis D, Gre'goire J, Mikolajczak M (2011) Emotional plasticity: Conditions of improving emotional competence in adulthood. Journal of Applied Psychology 96: 827839.

17. Levi, L. (1987). Fitting work to human capacities and needs improvements in the contents and organization of work. In kaline et al., Psychological Factors at work.

18. Mayer, J. D., \& Salovey, P. (1997). What is emotional intelligence. In P. Salovey \& D. Sluyter (Eds.), Emotional development and emotional intelligence: Educational implications (pp. 3-31). New York: Basic Books.

19. Mayer, J. D., and Salovey, P. "What is emotional intelligence?" in Emotional Development and Emotional. New York, NY, USA,.

20. Nelis D, Quoidbach J, Hansenne M, Weytens F, Dupuis P et al. (2011). Increasing Emotional Competence Improves Psychological and Physical Well- Being, Social Relationships, and Employability. Emotion 11: 354-366.

21. Pollard, Elizabeth, L., and Lee, Patric, D. (2003). Child well-being: A systematic review of the literature, Social Indicators Research, 61, 60.

22. Pushkar D., Bukowski M. W., Schwartzman A. E., D. M. Building Interventions Based on Theory and Research. 
23. Pushkar, M. W. Competence Across the Lifespan: Building Interventions Based on Theory and Research, D.

24. Qualter, P., Gardner, K. J., and Whiteley, H. E. (2007). "Emotional intelligence: review of research and educational implications," Pastoral Care in Education, vol. 25, no. 1, pp. 11-20.

25. Qualter, P., Gardner, K. J., and Whiteley, H. E. (2007). "Emotional intelligence: review of research and educational implications," Pastoral Care in Education, vol. 25, no. 1, pp. 11-20.

26. Robins, R. W., John, O. P., Caspi, A., Moffitt, T. E., and Stouthamer-Loeber, M. (1996). "Resilience, over controlled, andUnder controlled boys: three replicable personality types," Journal of Personality and Social Psychology, vol. 70, no. 1, pp. 157-171.

27. Salovey, P. and Sluyter, D. (1997). Intelligence: Educational Implications Eds., Basic Books, New York, NY, USA.

28. Shipman, K . L., and Zeman, J. (2001). Socialization of children's emotion regulation in mother-child dyads: a developmental psychopathology perspective. Dev. Psychopathol. 13, 317-336.doi:10.1017/S0954579401002073.

29. Singh, J., and Gupta, A. (2001). Well Being Scale, Department of Education, Chandigarh: Panjab University.

30. Wang, N., Young, T., Wilhite, S. C., and Marczyk, G. (2011). “Assessing students' emotional competence in higher education: development and validation of the widener emotional learning scale," Journal of Psychoeducational Assessment, vol. 29, no. 1, pp. 47-62.

31. Wang, N., Young, T., Wilhite, S. C., and Marczyk, G. (2011). "Assessing students' emotional competence in higher education: development and validation of the widener emotional learning scale," Journal of Psychoeducational Assessment, vol. 29, no. 1, pp. 47-62.

32. White, R.W. (1959). Motivation Reconsidered: The Concept of Competence. Psychological Review, 66,297-833.

33. Zeidner, M., and Olnick-Shemesh, D. (2010). "Emotional intelligence and subjective well-being revisited," Personality and Individual Differences, vol. 48, no. 4, pp. 431435. 